\title{
Correction to: Surgeon-performed point-of-care ultrasound for acute cholecystitis: indications and limitations: a European Society for Trauma and Emergency Surgery (ESTES) consensus statement
}

\author{
Jorge Pereira ${ }^{1}(0)$ Gary A. Bass ${ }^{2,3} \cdot$ Diego Mariani $^{4} \cdot$ Bogdan D. Dumbrava $^{3}$. Andrea Casamassima ${ }^{5}$. \\ António Rodrigues da Silva ${ }^{6} \cdot$ Luis Pinheiro $^{7} \cdot$ Isidro Martinez-Casas $^{8} \cdot$ Luca Ponchietti $^{10} \cdot$ Mauro Zago $^{9}$
}

Published online: 8 November 2019

(c) Springer-Verlag GmbH Germany, part of Springer Nature 2019

\section{Correction to: \\ European Journal of Trauma and Emergency Surgery https://doi.org/10.1007/s00068-019-01197-z}

Unfortunately, the author Luca Ponchietti was omitted in the original publication. Please find the correct author list here:

Jorge Pereira, Gary A. Bass, Diego Mariani, Bogdan D. Dumbrava, Andrea Casamassima, António Rodrigues da Silva, Luis Pinheiro, Isidro Martinez-Casas, Luca Ponchietti, Mauro Zago

The original article can be found online at https://doi.org/10.1007/ s00068-019-01197-z.

Jorge Pereira

docjota@netcabo.pt

1 Division of Hepatobiliary Surgery, Department of General Surgery, Hospital São Teotónio, Viseu, Portugal

2 Department of Surgery, Tallaght University Hospital, Dublin 24, Ireland

3 Royal College of Surgeons in Ireland, 123 St Stephens Green, Dublin 2, Ireland

4 Department of Emergency General Surgery, Legnano Hospital, ASST Ovest Milanese, Legnano, MI, Italy

5 Department of Emergency Medicine, Ospedale "S. Maria delle Stelle", ASST Melegnano e Martesana, Melzo, MI, Italy
6 Division of Colorectal Surgery, Department of General Surgery, Pedro Hispano Hospital, Matosinhos, Portugal

7 Division of Esophagogastric Surgery, Department of General Surgery, Hospital São Teotónio, Viseu, Portugal

8 Department of General Surgery, Hospital Médico-Quirúrgico, Jaén, Spain

9 Division of Minimally Invasive Surgery and Surgical Oncology, Department of Surgery, Policlinico San Pietro, Ponte San Pietro, Bergamo, Italy

10 Department of General Surgery, Torrevieja University Hospital, Alicante, Spain 